\title{
Synoptic patterns associated with wildfires caused by lightning in Castile and Leon, Spain
}

\author{
E. García-Ortega ${ }^{1}$, M. T. Trobajo ${ }^{2}$, L. López ${ }^{1}$, and J. L. Sánchez ${ }^{1}$ \\ ${ }^{1}$ Group of Atmospheric Physics, University of León, 24071-León, Spain \\ ${ }^{2}$ Department of Mathematics, University of León, 24071-León, Spain
}

Received: 16 November 2010 - Revised: 13 January 2011 - Accepted: 4 February 2011 - Published: 16 March 2011

\begin{abstract}
The Iberian Peninsula presents the highest number of wildfires in Europe. In the NW of Spain in particular, wildfires are the natural risk with the greatest economic impact in this region. Wildfires caused by lightning are closely related to the triggering of convective phenomena. The prediction of thunderstorms is a very complex task because these weather events have a local character and are highly dependent on mesoscale atmospheric conditions. The development of convective storms is directly linked to the existence of a synoptic environment favoring convection. The aim of this study is to classify the atmospheric patterns that provide favorable environments for the occurrence of wildfires caused by lightning in the region of Castile and Leon, Spain. The database used for the study contains 376 wildfire days from the period 1987-2006. NCEP data reanalysis has been used. The atmospheric fields used to characterise each day were: geopotential heights and temperatures at $500 \mathrm{hPa}$ and $850 \mathrm{hPa}$, relative humidity and the horizontal wind at $850 \mathrm{hPa}$. A Principal Component Analysis in T-mode followed by a Cluster Analysis resulted in a classification of wildfire days into five clusters. The characteristics of these clusters were analysed and described, focusing particularly on the study of those wildfire days in which more than one wildfire was detected. In these cases the main feature observed was the intensification of the disturbance typical of the cluster to which the wildfire belongs.
\end{abstract}

\section{Introduction}

Wildfires are the main disruptive and destructive agent in the natural environment of Castile and Leon, Spain, the largest region in Europe. Covering a total of $94225 \mathrm{~km}^{2}$, and with

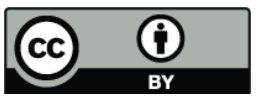

Correspondence to: E. García-Ortega (eduardo.garcia@unileon.es) a forest area of nearly $50000 \mathrm{~km}^{2}$, Castile and Leon lies in the NW of the Iberian Peninsula (Figs. 1 and 2) and comprises nearly $20 \%$ of the land in Spain. From the administrative point of view, this region is divided into nine provinces: Leon, Palencia, Burgos, Zamora, Valladolid, Soria, Salamanca, Avila and Segovia. Most of the land in Castile and Leon consists of a large portion of Spain's Central Plateau, surrounded by mountainous regions. The Plateau is a high plain with an average altitude of about $800 \mathrm{~m}$. Along the north of Castile and Leon lies the Cantabrian Mountain Range, to the east the Iberian Mountain Range and to the south the Central System. The forest area is mainly concentrated on the borderline areas of the region: $\mathrm{N}, \mathrm{NW}, \mathrm{S}$ and E.

On the Iberian Peninsula, both in Spain and Portugal, wildfires often cause severe catastrophes in ecosystems as well as many casualties. The countries in the south of Europe (Spain, Portugal, France, Italy and Greece) present the largest number of wildfires in the continent. The NW of the Iberian Peninsula presents the largest number of fires in Europe $(50 \%)$, followed by Southern Italy $(10 \%)$ and the triangle Provence-Tuscany-Corsica (7\%). The NW of the Iberian Peninsula has the largest areas affected by wildfires too $(\mathrm{CE}$, 1996, 1998).

Castile and Leon is one of the regions with the most forest land in the whole of Europe and, consequently, wildfires represent an important risk for the population. $8 \%$ of the fires that occur in this region are due to lightning during thunderstorms, although in some years they account for more than $20 \%$ of the total surface devastated by fire. The forecast of the meteorological situations that represent a high risk for the occurrence of wildfires caused by lightning is a fundamental task towards minimising this risk.

Estimating wildfire risk in a particular area is essential for environmental management in general. It is difficult to determine the probability of occurrence of wildfires caused by human activities because a number of different factors are

Published by Copernicus Publications on behalf of the European Geosciences Union. 


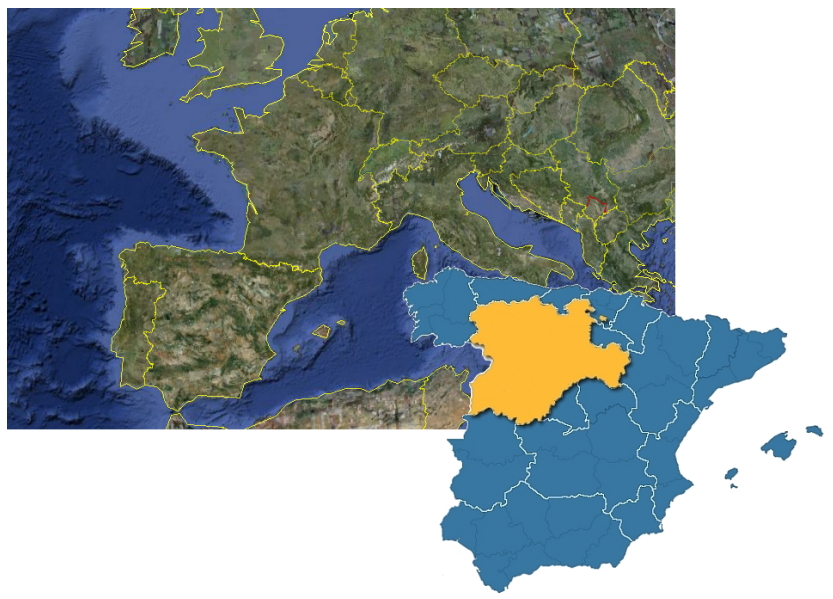

Fig. 1. Geographic location of Castile and Leon.

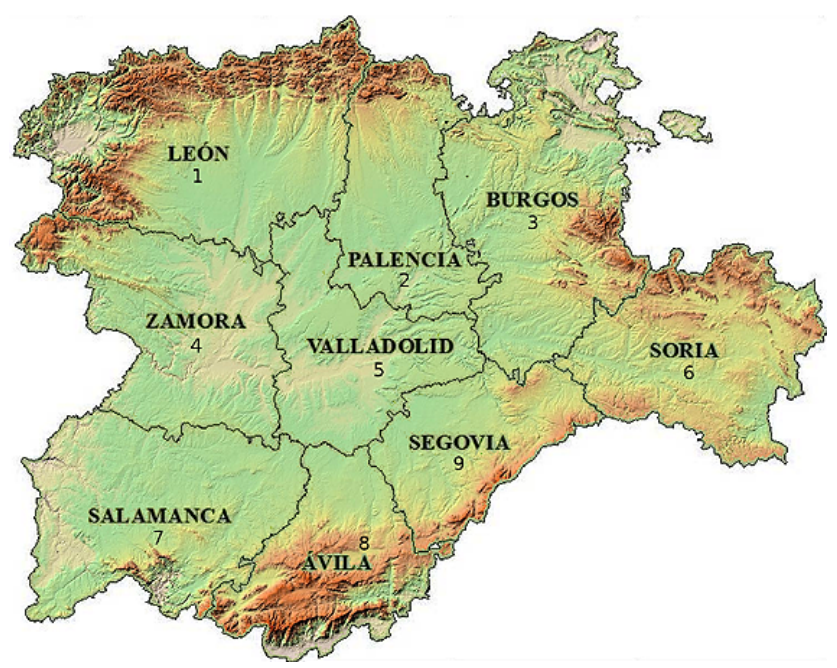

Fig. 2. Provinces of Castile and Leon numbered.

involved. However, in the case of wildfires caused by lightning, the weather variables (among others related to the vegetation or the physiography) may explain a high percentage of the probability of occurrence.

Weather influences the behavior of wildfires directly, by means of the effect it has on the humidity of the fuel, or indirectly, due to the important role of the wind in the propagation of the fire and in the heat transfer by convection. Climatic and atmospheric factors are key issues both in the processes of ignition and propagation (Pyne et al., 1996; Kunkel, 2001). In fact, for obtaining fire risk indices we need to take into account several meteorological fields as well as others related to the state of the combustible vegetation (Viegas et al., 1999).

Flaningan and Wotton (2001) have linked large-scale atmospheric patterns with wildfire activity. Connections have been found between El Niño Southern Oscillation (ENSO) and fire activity in the USA (Swetnam and Betancourt, 1990). The relations between large-scale circulation patterns and wildland fire severity have also been studied in Canada (Skinner et al., 2002) and Portugal (Pereira et al., 2005). Trigo et al. (2006) studied the relations between the positive anomalies of the $850 \mathrm{hPa}$ temperature field and a devastating sequence of large fires in Portugal in 2003. The use of forecast models has enabled us to study the impact of atmospheric circulation on fire activity (Roads et al., 1991).

Lightning is a clear risk factor in the occurrence of wildfires (Morris, 1934; Fuquay et al., 1979). Lightning is a major cause of weather-related deaths, property damage and natural forest fires (Wierzchowski et al., 2002). It plays an important role in devastating fires that burn large areas. Critical fire-weather conditions are the prime ingredients needed to fuel a fire that may rage for long periods of time. The land area affected by this type of fire is generally larger than in the case of fires with a different origin because storms often bring with them strong and erratic winds making fire extinction more difficult. Most summer storms occur in mountainous regions and during the night, thus contributing to larger affected areas. The linkage between wildfires caused by lightning and the atmospheric circulation patterns is stronger than in the case of fires due to other causes, as the atmospheric factor introduces a connection: lightning as the direct and primary cause of fire.

Lightning is directly related to convective activity (Petersen and Rutledge, 1998; Rivas and de Pablo, 2003). The formation of storms requires the interaction of several dynamic and thermodynamic mechanisms on different scales. The occurrence of lightning in convective clouds is coupled to cumulonimbus cloud dynamics and microphysics. The development of cumulonimbus clouds is governed by processes occurring in the surrounding atmosphere. The local character of storms is the main obstacle in any meteorological study of the convective activity in a particular area. Thunderstorms develop within environments that exhibit high spatial and temporal variability (Brooks et al., 1994) and convective cells with lightning are meteorological phenomena with a limited spatial and temporal resolution. Predicting the occurrence of convective storms, which often occur with lightning, is one of the most complicated tasks in weather forecasting. Rorig and Ferguson (1999) determined that the $850 \mathrm{hPa}$ moisture and the $850-500 \mathrm{hPa}$ temperature difference were very useful for establishing the likelihood of fires due to dry lightning in the NW of the US.

Convective systems depend primarily on large-scale processes that develop a favorable thermodynamic structure, whereas processes on a mesoscale act basically at the beginning of the convective phenomenon. Kassomenos (2010) linked synoptic weather types with large forest fires that took place in Greece during the 20-year period 1985-2004. The synoptic scale atmospheric patterns and their relationship with local weather play an important role in the occurrence of hailstorms, through the controlling effect on the formation 
Table 1. Forest surface of the province of Castile and Leon $\left(\mathrm{km}^{2}\right)$.

\begin{tabular}{lccrrrrrrr}
\hline & 1 & 2 & 3 & \multicolumn{1}{c}{4} & 5 & 6 & 7 & 8 & 9 \\
\hline Sup. forestal & 10003.13 & 2511.38 & 6811.35 & 4826.05 & 1451.36 & 5971.43 & 7956.79 & 5255.49 & 3290.33 \\
Sup. total & 15580.85 & 8052.51 & 14291.04 & 10561.26 & 8110.49 & 10306.42 & 12349.95 & 8050.15 & 6922.75 \\
\hline
\end{tabular}

of local thermodynamic regimes. Millán et al. (1998) studied the interactions between the synoptic conditions at 700 and $500 \mathrm{hPa}$ and regional winds, and their implications in the dynamics of fires at the Spanish Mediterranean Coast.

A detailed classification of the synoptic situations on the days with wildfires due to natural causes will be a powerful tool to improve fire risk forecast and to establish more effective alarm systems. The classifications based on the use of multivariate statistics make it possible to obtain objective and reliable results. The main objective of this study is to make a synoptic classification of the atmospheric patterns of wildfire days (WD) caused by lightning in Northwestern Spain and to determine the synoptic characteristics corresponding to WD for a period of twenty years (1987-2006) and to improve the forecast.

The paper is organised as follows: in Sect. 2 we present the methodology and databases used. In Sect. 3, we present the results of the objective classification and we analyse some cases corresponding to the main hailstorm days of every cluster. In Sect. 4 the conclusions of the study are presented.

\section{Data bases and methodology}

\subsection{Data bases and WD distribution}

During the period from 1987 to 2006 a total of 376 WD were recorded, with 960 wildfires caused by lightning in Castile and Leon covering more than 1 ha. This threshold was set to avoid including smaller fires caused by lightning but then immediately extinguished by rain. The study will focus on wildfires caused by dry storms.

The wildfires were detected by the Center for the Defense against Fire (CDF) of the Regional Government in Castile and Leon using a dense network of observers and satellite teledetection systems. In order to analyse the distribution of wildfires in the study period, we have numbered the provinces of Castile and Leon from west to east and from north to south as we see in Fig. 2. The forest land in the study area is unevenly distributed (see Table 1). Over $20 \%$ of this surface concentrates in the province of Leon only (no. 1).

The synoptic characteristics of the atmosphere on the 376 WD were classified. A total of 960 fires were registered in these WD, scattered over the whole study zone. As the forest areas are not distributed homogeneously in the region, wildfires follow the same pattern. The province of Leon (no. 1) has registered the largest number of WD and of wild-
Table 2. Number of wildfires per lightning event in the provinces of Castile and Leon between 1987 and 2006.

\begin{tabular}{cccccccccc}
\hline & 1 & 2 & 3 & 4 & 5 & 6 & 7 & 8 & 9 \\
\hline Fires & 313 & 34 & 71 & 90 & 40 & 36 & 134 & 157 & 85 \\
Freq. & 32.6 & 3.5 & 7.4 & 9.4 & 4.2 & 3.8 & 14.0 & 16.3 & 8.8 \\
\hline
\end{tabular}

Table 3. Number of WD per month in Castile and Leon between 1987 and 2006.

\begin{tabular}{cccccccc}
\hline & Apr & May & Jun & Jul & Aug & Sept & Total \\
\hline No. of WD & 9 & 23 & 67 & 113 & 108 & 56 & 376 \\
\hline
\end{tabular}

fires (313 fires, 32.6\%; see Table 2). In fact, the province of Leon is the third in Spain with the largest number of wildfires. In particular, the west of Leon and the NW of Zamora comprise the forest areas most widely affected by fires in the region of Castile and Leon (42\%), followed by the southern provinces: Avila, Segovia and Salamanca (39.1\%). In Burgos and Palencia the wildfires are concentrated in the north the $11.9 \%$. Valladolid and Soria account for only $8 \%$ of the total of wildfires.

Considering the topography, the spatial distribution of the forest land and the geographic distribution of the wildfires registered, the study area has been divided into two groups: the NorthWestern Group (NWG) formed by the provinces 1 to 4 and registering $52.9 \%$ of the fires, and the SouthEastern Group (SEG) formed by the provinces 5 to 9 and registering $46.8 \%$. The forest land in the NWG is mainly concentrated in the Cantabrian Range and has an area of $24151 \mathrm{~km}^{2}(50.2 \%$ of the total), spreading to the west over the Mounts of Leon to the region of Tras-os-Montes in Portugal. The forest land in the SEG is mainly concentrated in the Central Mountain Range and the NW of the Iberian Mountain System and has a land area of $23925 \mathrm{~km}^{2}$ (49.3\% of the total).

The monthly distribution of WD can be observed in Table 3. Of the total $376 \mathrm{WD}, 221 \mathrm{WD}$ occurred in the months of July and August $(58.8 \%)$. The highest maximum and minimum temperatures in Castile and Leon are registered in these months (the monthly mean of the maximum daily temperatures is $26.5^{\circ} \mathrm{C}-30.5^{\circ} \mathrm{C}$ and of the minimum daily temperatures $12.0^{\circ} \mathrm{C}-15.0^{\circ} \mathrm{C}$ ). 


\subsection{Methodology}

The final aim of this study is to develop an objective classification based on the identification of the meteorological situations that may lead to convective phenomena including storms with lightning. In order to characterise the atmospheric conditions of the WD on a synoptic scale, gridded reanalysis data from the National Centers for Environmental Prediction (NCEP) were used, with a latitude-longitude resolution of $2.5^{\circ} \times 2.5^{\circ}$. The area selected comprises the domain from $30^{\circ} \mathrm{N}$ to $50^{\circ} \mathrm{N}$ and from $20^{\circ} \mathrm{W}$ to $10^{\circ} \mathrm{E}$. The window dimensions were selected, on the one hand, in an effort to be consistent with the synoptic scale analysis of this study, and on the other, to avoid circulation features of regions far from the study area which could influence the results of the multivariate analysis. Taking into account that in most cases, according to $\mathrm{CDF}$ data, the detection of fires is between 12:00 UTC and 20:00 UTC, NCEP data files at 12:00 UTC were chosen as being the most representative ones.

The dynamic and thermodynamic state of the atmosphere was characterised by a group of seven atmospheric fields corresponding to the levels of $500 \mathrm{hPa}$ and $850 \mathrm{hPa}$. This initial group of fields provided relevant information on the atmospheric status at mid and low levels, highly important to determine favorable environments for the development of convection. The ensemble consisted of the $500 \mathrm{hPa}$ and $850 \mathrm{hPa}$ geopotential height and temperature $\left(\phi_{500}, \phi_{850}, T_{500}, T_{850}\right)$, the relative humidity $\left(\mathrm{rh}_{850}\right)$ and the two components of horizontal wind $\left(u_{850}, v_{850}\right)$ at $850 \mathrm{hPa}$. In order to obtain the atmospheric pattern classification of the $376 \mathrm{WD}$ within the selected geographical area, a Principal Component Analysis (PCA) was carried out, followed by a Cluster Analysis (CA) of the days, based on the retained principal component loadings. Days participating with similar loadings on the extracted components were clustered together. R software was used for multivariate statistics.

The PCA (Richman, 1986; Yarnal, 1993) is not only designed as a data reduction technique, but also as a method which ensures that only the fundamental variation modes of the data are considered for the clustering process. The PCA was applied in T-mode with a correlation matrix, using the time steps as variables and the grid points as observations. Several authors (Bärring, 1987; Preisendorfer, 1988; Jolliffe, 2002) have used different criteria to decide the number of PCs to retain so as to discriminate between signal and noise. In this case, we have considered only the most important components that account for at least $90 \%$ of the total variance.

CA was then applied. The CA is the application of an algorithm devised for grouping the objects (days in this case, described by their meteorological fields) into a number of classes, whereby objects within classes are similar in some respect and different from those in other classes. The days with similar loadings on the extracted components were clus- tered together. PCA was carried out for each field, and a sole CA applied to the total of loadings collected.

The non-hierarchical k-means method (Anderberg, 1973) was used and the Euclidean distance was taken as the similarity index. This method minimises the sum of the intra group sum of squares $(D)$, which decreases as the number of groups $(k)$ increases. The cluster number needs to be identified before the algorithms can proceed, selecting the optimum number when the decrease in $D$ is not significant. Gong and Richman (1995) showed that non-hierarchical methods outperformed hierarchical techniques. CA also was carried out using the hierarchical Ward method, in order to study and support the results obtained with the k-means method. However, the decision regarding the number of groups is not a completely objective task, as a degree of subjectivity is present, based on the researchers knowledge.

\section{Results}

\subsection{Objective classification}

After applying the PCA to the initial group of meteorological fields, five components were stored for $\phi_{500}$, seven components were stored for $\phi_{850}$, nine for $T_{500}$, four for $T_{850}$, sixteen components for $\mathrm{rh}_{850}$, twelve and eleven for $u_{850}$ and $v_{850}$ horizontal components of wind were selected (Table 4).

As a result, the CA was applied to the total matrix of 64 loadings of the 376 events. The Euclidean distance was computed from $k=2$ to $k=20$ showing a minimum decrease for $k=5$, which was the optimal cluster number considered. So the 376 WD were classified into 5 clusters known as CL1, CL2,..., CL5, following the order assigned to each cluster during the grouping process. Clusters 4 and 1 have fewer elements: 53 and $64 \mathrm{WD}$, respectively. Clusters 3 and 2 have 76 and $80 \mathrm{WD}$, respectively, and cluster 5 has the largest number of elements, with 103 WD. For the physical interpretation of the results we computed the mean values of the atmospheric fields of the WD in each cluster element (CL) (see Fig. 3). The results do not represent a real atmospheric pattern, but they do provide relevant information on the main features of each CL.

As far as the monthly distribution of clusters is concerned, in April the situations classified in CL2 and CL4 are the most frequent ones, resulting in anomalous patterns for that date. The small number of WD in this month does not provide conclusive results. During the month of May (Table 5), 35.0\% of WD belong to CL1. 26.9\% and 23.9\% of WD in June belong to CL3 and CL5. In July and August more than 55.0\% of WD were classified into CL5 and CL2, respectively. From May to August we observed a gradual decrease in the relative load of CL1 and CL3, as well as a gradual increase in the relative load of clusters CL2 and CL5. It is thus clear that in the summer months with more wildfires, CL2 and CL5 represent the two most common synoptic situations in WD (Table 5). 
Table 4. Principal components of geopotential height and temperature at $500 \mathrm{hPa}$ and $850 \mathrm{hPa}$ and relative humidity, $u$ and $v$ components of wind at $850 \mathrm{hPa}$. PC: Principal Component; var. expl.: proportion of variance explained; cum. prop.: cumulative proportion.

\begin{tabular}{|c|c|c|c|c|c|c|c|c|c|c|c|}
\hline $\mathrm{PC}$ & var. expl. & cum. prop. & $\mathrm{PC}$ & var. expl. & cum. prop. & $\mathrm{PC}$ & var. expl. & cum. prop. & $\mathrm{PC}$ & var. expl. & cum. prop. \\
\hline \multicolumn{3}{|c|}{$500 \mathrm{hPa}$ geopot. height } & \multicolumn{3}{|c|}{$850 \mathrm{hPa}$ geopot. height } & \multicolumn{3}{|c|}{$850 \mathrm{hPa}$ temperature } & \multicolumn{3}{|c|}{$850 \mathrm{hPa}$ rel. humidity } \\
\hline 1 & 38.198 & 38.198 & 1 & 35.808 & 35.808 & 1 & 32.431 & 32.431 & 1 & 21.234 & 21.234 \\
\hline 2 & 28.025 & 66.223 & 2 & 17.935 & 53.743 & 2 & 28.389 & 60.820 & 2 & 14.503 & 35.737 \\
\hline 3 & 13.601 & 79.824 & 3 & 11.869 & 65.611 & 3 & 26.255 & 87.075 & 3 & 12.475 & 48.212 \\
\hline 4 & 6.191 & 86.015 & 4 & 8.645 & 74.257 & 4 & 3.689 & 90.764 & 4 & 10.581 & 58.793 \\
\hline 5 & 4.677 & 90.692 & 5 & 8.081 & 82.338 & \multicolumn{3}{|c|}{$850 \mathrm{hPa}$ u comp. wind } & 5 & 8.047 & 66.840 \\
\hline \multicolumn{3}{|c|}{$850 \mathrm{hPa}$ v comp. wind } & 6 & 5.502 & 87.840 & 1 & 27.043 & 27.043 & 6 & 4.726 & 71.566 \\
\hline 1 & 19.926 & 19.926 & 7 & 4.383 & 92.223 & 2 & 13.568 & 40.611 & 7 & 2.545 & 74.112 \\
\hline 2 & 18.619 & 38.544 & \multicolumn{3}{|c|}{$500 \mathrm{hPa}$ Temp. } & 3 & 11.883 & 52.494 & 8 & 2.350 & 76.462 \\
\hline 3 & 15.863 & 54.407 & 1 & 24.653 & 24.653 & 4 & 8.343 & 60.837 & 9 & 2.225 & 78.687 \\
\hline 4 & 14.235 & 68.642 & 2 & 18.021 & 42.675 & 5 & 5.651 & 66.487 & 10 & 2.124 & 80.810 \\
\hline 5 & 4.132 & 72.774 & 3 & 14.849 & 57.524 & 6 & 5.277 & 71.764 & 11 & 2.044 & 82.854 \\
\hline 6 & 3.534 & 76.308 & 4 & 13.532 & 71.056 & 7 & 5.029 & 76.794 & 12 & 1.803 & 84.658 \\
\hline 7 & 3.265 & 79.573 & 5 & 6.036 & 77.091 & 8 & 3.226 & 80.020 & 13 & 1.574 & 86.232 \\
\hline 8 & 3.182 & 82.755 & 6 & 5.398 & 82.490 & 9 & 3.078 & 83.098 & 14 & 1.427 & 87.659 \\
\hline 9 & 2.870 & 85.625 & 7 & 2.992 & 85.482 & 10 & 2.801 & 85.899 & 15 & 1.422 & 89.082 \\
\hline 10 & 2.758 & 88.383 & 8 & 2.525 & 88.006 & 11 & 2.781 & 88.680 & 16 & 1.263 & 90.345 \\
\hline 11 & 2.115 & 90.498 & 9 & 2.128 & 90.134 & 12 & 2.435 & 91.155 & & & \\
\hline
\end{tabular}

Table 5. Relative frequency of every CL by month.

\begin{tabular}{lcccccc}
\hline Month & WD & CL1 & CL2 & CL3 & CL4 & CL5 \\
\hline Apr & 9 & 0.11 & 0.33 & 0.11 & 0.33 & 0.11 \\
May & 23 & 0.35 & 0.17 & 0.17 & 0.13 & 0.17 \\
Jun & 67 & 0.16 & 0.18 & 0.27 & 0.15 & 0.24 \\
Jul & 113 & 0.17 & 0.27 & 0.17 & 0.12 & 0.28 \\
Aug & 108 & 0.12 & 0.23 & 0.18 & 0.15 & 0.32 \\
Sep & 56 & 0.21 & 0.11 & 0.27 & 0.14 & 0.27 \\
\hline
\end{tabular}

\subsubsection{Cluster 1}

CL1 contains 64 WD. In May the relative load of CL1 is higher than in the remaining clusters (see Table 5). In June, July and August the importance of this cluster decreases and then increases again in September. These synoptic situations are more typical of spring or late summer than of the actual summer months. The mid level fields present a pattern defined by the existence of a low pressure system with a very cold air parcel. The $\phi_{500}$ is characterised by a cut-off low centered in the Northwest of Spain (see Fig. 3) and an associated low-temperature center $\left(T_{500}\right)$ with minimum values lower than $260 \mathrm{~K}$, lower than the values in the remaining clusters. The disturbance at mid levels extends until $850 \mathrm{hPa}$. The structure described by $\phi_{850}, T_{850}, \mathrm{rh}_{850}$ and the horizontal component of wind at $850 \mathrm{hPa}$ causes an intense advection of warm and dry air from the south of the Iberian Peninsula. This fact, together with the cold air at upper levels, constitutes a favorable environment for the development of convection in the study area.
Table 6. Monthly frequency of WD according to the CA results.

\begin{tabular}{lccccccc}
\hline Cluster & WD & Apr & May & Jun & Jul & Aug & Sep \\
\hline CL1 & 64 & 0.02 & 0.13 & 0.17 & 0.30 & 0.20 & 0.19 \\
CL2 & 80 & 0.04 & 0.05 & 0.15 & 0.38 & 0.31 & 0.08 \\
CL3 & 76 & 0.01 & 0.05 & 0.24 & 0.25 & 0.25 & 0.20 \\
CL4 & 53 & 0.06 & 0.06 & 0.19 & 0.25 & 0.30 & 0.15 \\
CL5 & 103 & 0.01 & 0.04 & 0.16 & 0.31 & 0.34 & 0.15 \\
\hline
\end{tabular}

\subsubsection{Cluster 2}

CL2 contains 80 WD. $37.5 \%$ and $31.3 \%$ of the WD in CL2 are observed during the months of July and August, respectively (see Table 6). The $\phi_{500}$ reveals a slight trough tilted to the SW and affecting mainly the NW of the peninsula. The arrival of troughs from the Atlantic over the Iberian Peninsula often causes atmospheric instability in the summer months. At $850 \mathrm{hPa}$ it was found that the trough was in advance with respect to $\phi_{500}$ with maximum values of $\mathrm{rh}_{850}$ over the NE of the study area. This disturbance affects the peninsula causing a counterclockwise rotation of wind in the south of Spain. $T_{850}$ is around $288 \mathrm{~K}$ over Castile and Leon and the horizontal wind at $850 \mathrm{hPa}$ has a weak southern component in the south of the study region. This configuration results in convective activity and lightning events mainly in the south of the study area. 

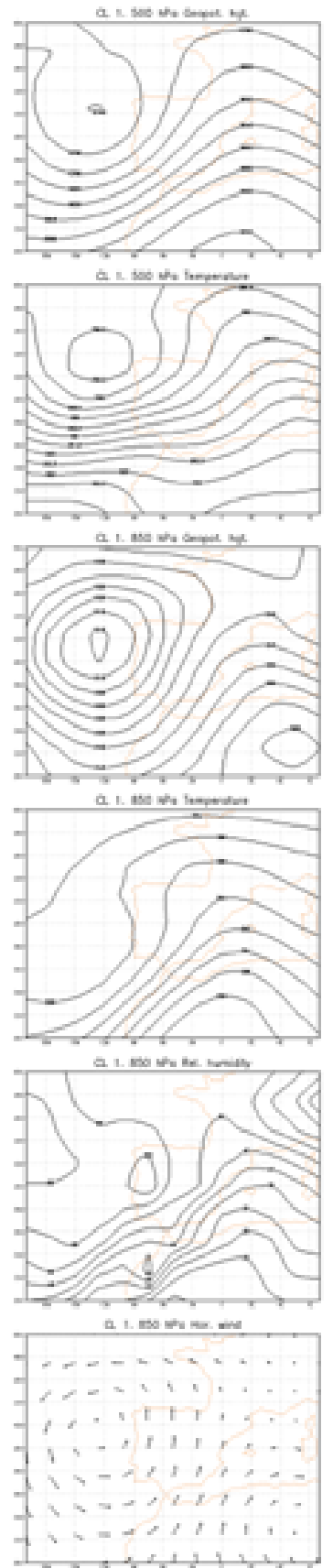
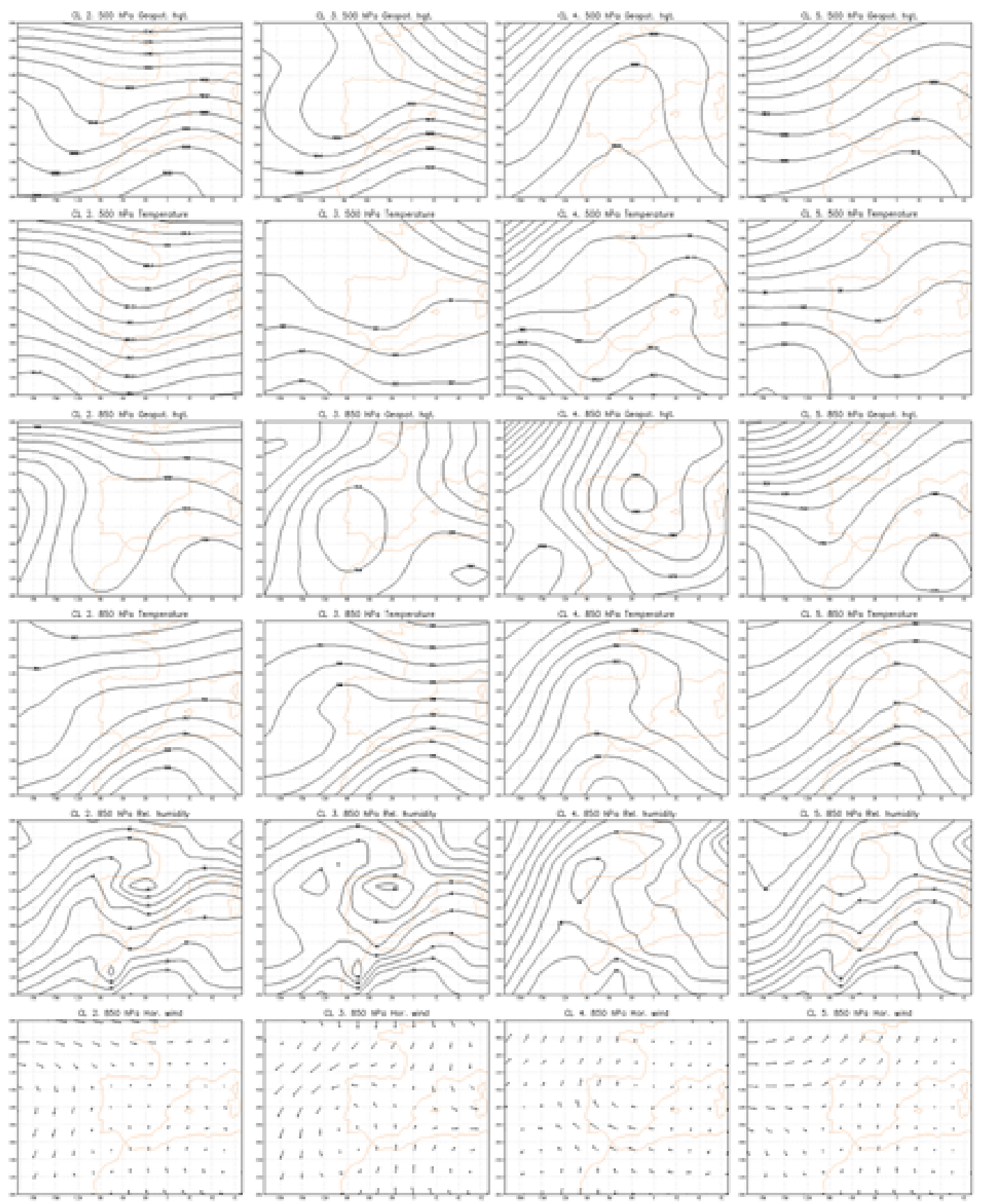

Fig. 3. Results obtained by the Cluster Analysis. The clusters are numbered following the order obtained in the k-mean output. Clusters 1 to 5 labelled as CL1, CL2, ., CL5 in the columns. The atmospheric fields are in rows: $\phi_{500}(\mathrm{gpm}), T_{500}(\mathrm{~K}), \phi_{850}(\mathrm{gpm}), T_{850}(\mathrm{~K}), \mathrm{rh}_{850}$ (\%) and horizontal wind direction at $850 \mathrm{hPa}$ from top to bottom.

\subsubsection{Cluster 3}

CL3 contains 76 WD. The months of June and September (see Table 5) present the highest relative frequencies of WD associated to CL3 (in September together with CL5). This cluster is characterised by a $500 \mathrm{hPa}$ trough tilted to the southwest over the Iberian Peninsula and an associated arrival of cold air from the European continent (see Fig. 3). At
$850 \mathrm{hPa}$ a low is centered over the SW of the Iberian Peninsula. The maximum values of the $\mathrm{rh}_{850}$ lie over the north of Spain, as in CL2. The intensity and the location of the low favor the advection of warm and dry air from the north of Africa towards Spain, and particularly over Castile and Leon. The joint action of the mid level trough and the $850 \mathrm{hPa}$ low generate instability in the study area favoring the occurrence of convective events. 


\subsubsection{Cluster 4}

CL4 contains 53 WD. This is the cluster with the smallest number of elements, so this type of atmospheric pattern is the least frequent one. The relative load of CL4 is low, although it increases from June to August (see Table 6). The $\phi_{500}$ reveals a ridge from the north of Africa, affecting most of the peninsula. This ridge precedes the arrival of a trough from the Atlantic (see Fig. 3). At $850 \mathrm{hPa}$, a high pressure area lies over the SW of Europe and affects Spain, mainly the NE of the Iberian Peninsula. A very warm and dry air mass affects the $\mathrm{W}$ of the Peninsula at low levels. The $850 \mathrm{hPa}$ wind turns clockwise bringing winds from the south over the study area. In this situation, we observed the formation of prefrontal storms with lightning, especially in the NWG, which lies closer to the trough coming in at $500 \mathrm{hPa}$.

\subsubsection{Cluster 5}

CL5 contains 103 WD. This is the cluster with the largest number of WD, and therefore represents the most frequent situations. In the months of July and August this is the dominating synoptic pattern. In August, $32.4 \%$ of WD belong to CL5 (see Table 5). As in CL2, the pattern at $500 \mathrm{hPa}$ is characterised by the arrival of a trough from the Atlantic, though with a longer wave length. This disturbance affects first the western half of the Iberian Peninsula and then crosses it from $\mathrm{W}$ to E. This pattern can also be observed at $850 \mathrm{hPa}$. The trough is preceded by an African ridge at mid levels and a high-pressure system at $850 \mathrm{hPa}$. The boundary between both enhances the advection of warm and dry air from northern Africa.

\subsection{Spatial distribution of wildfires}

In CL2, CL3 and CL5 the wildfires are evenly distributed between the NWG and the SEG (see Table 7). However, in CL1 and CL4 it was found that nearly $60 \%$ of the wildfires occurred in the NWG, compared to $40 \%$ in the SEG. This difference makes it difficult to associate the patterns of one particular cluster to the fire risk in the NWG or the SEG. Nonetheless, in the cases of CL1 and CL4, the relative position of the synoptic patterns at low and mid levels does explain the larger number of wildfires in the NWG.

The low in the $\phi_{500}$ graph of CL1 (Fig. 3) lies to the W of the Atlantic coast. The instability at mid and high levels is more obvious in the $\mathrm{W}$ of Castile and Leon. On the other hand, the low pressure system at $850 \mathrm{hPa}$, an extension of the disturbance at $500 \mathrm{hPa}$ on the same vertical, pushes away the ridge which was still affecting the E of the Peninsula. The NWG is therefore the most affected by the atmospheric instability responsible for the vertical updrafts. In CL4, virtually the whole of the Peninsula lies under the influence of a high ridge. However, this ridge is pushed east-
Table 7. WD and fires by CL.

\begin{tabular}{lccc|rr}
\hline Cluster & WD & Fires & Ratio & NWG fires & \multicolumn{1}{c}{ SEG fires } \\
\hline CL1 & 64 & 154 & 2.41 & $91(59 \%)$ & $63(41 \%)$ \\
CL2 & 80 & 153 & 1.91 & $76(50 \%)$ & $77(50 \%)$ \\
CL3 & 76 & 167 & 2.20 & $85(51 \%)$ & $82(49 \%)$ \\
CL4 & 53 & 223 & 4.21 & $128(57 \%)$ & $95(43 \%)$ \\
CL5 & 103 & 263 & 2.55 & $128(49 \%)$ & $135(51 \%)$ \\
\hline
\end{tabular}

wards by the trough coming in through the NW of Spain. This leads to an increased instability and the formation of prefrontal storms mostly in NWG.

\subsection{WD with more than one wildfire}

The database contains WD with a number of wildfires that ranges between 1 and 15 . The larger the number of wildfires on the same day, the more difficult it is to manage the means available for fire extinction, and consequently, more damage is caused. From an operational perspective, when 5 or more wildfires are detected, it becomes difficult to coordinate fire extinction brigades, so in these circumstances the prediction is particularly important.

Most wildfires belong to CL4 and CL5. Together they account for $50 \%$ of the wildfires registered. In other words, the synoptic patterns of these clusters are the most favorable ones for the development of dry storms. CL5 contains the largest number of WD, but only 263 wildfires. In contrast, CL4 contains 223 wildfires with only 53 WD. Table 7 shows that in CL4 the ratio between wildfires and WD is 4.21. This value is much higher here than in the other clusters. In fact, in 17 of the 53 WD in CL4 between 5 and 15 wildfires were registered.

The synoptic patterns obtained in the CA demonstrate the importance of CL4 and CL5 in relation to the number of wildfires registered, in particular in the case of CL4. In both cases the synoptic pattern at $850 \mathrm{hPa}$ seems to be decisive. In CL5 the arrival of a trough at low levels pushes away a high-pressure system over Algeria. The influence of this high locates isotherm $290 \mathrm{~K}$ over Castile and Leon, while $\mathrm{rh}_{850}$ reaches values of $45-50 \%$ and there is advection of warmer and drier air from the south. In CL4, the existence of a high over the NE of Spain is a peculiar factor favoring the entrance of warm and very dry air from the north of Africa. This air crosses the whole of the Iberian Peninsula and eventually reaches the study area. The $T_{850}$ map shows a higher temperature than in the rest of situations, between 292-294 K and a lower relative humidity of $30-35 \%$. These conditions at low levels lead to a warmer and drier environment than in the other clusters, where at $850 \mathrm{hPa}$ the isotherm over the study area is $288 \mathrm{~K}$ and the relative humidity is over $50 \%$. 

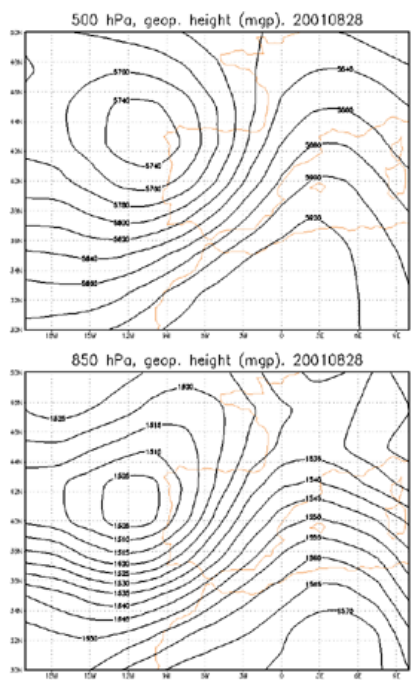

850 hPo, Rel. hum. (\%). 20010828
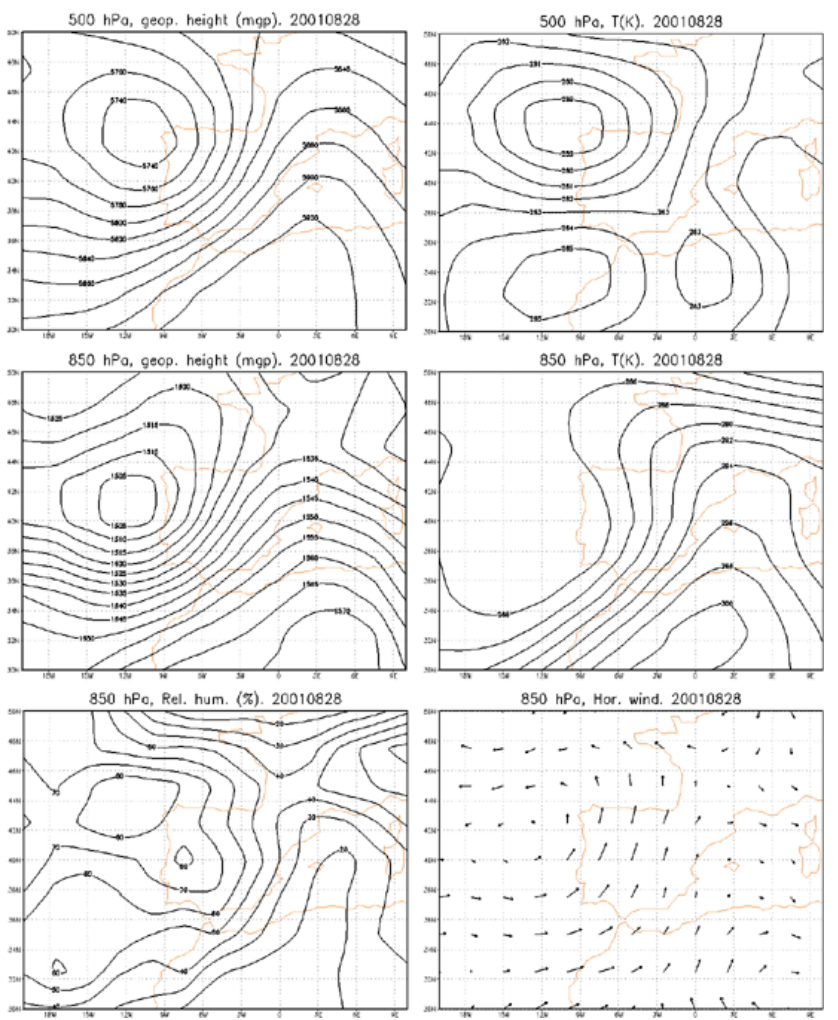

$850 \mathrm{hPO}, \mathrm{T}(\mathrm{K}) .20010828$

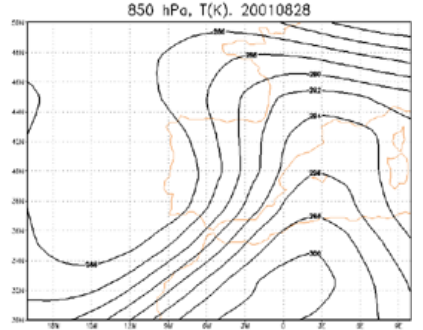

$850 \mathrm{hPo}$, Hor. wind. 20010828

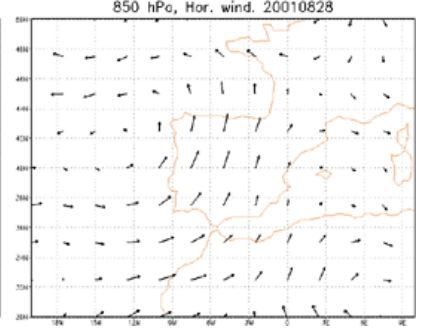

Fig. 4. NCEP reanalysis, 12:00 UTC. Date: 28 August 2001, CL1. The atmospheric fields shown are: $\phi_{500}(\mathrm{gpm}), T_{500}(\mathrm{~K}), \phi_{850}$ (gpm), $T_{850}(\mathrm{~K}), \mathrm{rh}_{850}(\%)$ and wind direction at $850 \mathrm{hPa}$, from left to right.

The days with several wildfires have a number of synoptic features that make them different from the typical values in the clusters. The depth of the disturbances either at $500 \mathrm{hPa}$ or at $850 \mathrm{hPa}$ accounts for the intense convective activity reflected in the lightning maps. We will now show the synoptic patterns of the WD with more wildfires in each cluster.

\subsubsection{CL1: case 20010828}

The $\phi_{500}$ (see Fig. 4) is similar to the one found in Fig. 3 for CL1, although the low pressure system is cut off, deeper and closer to the peninsula. The $\phi_{850}$ pattern shows that the disturbance to the west of Portugal is also deeper than the mean value of the cluster. The lightning map illustrates that the highest concentration of lightning affects the NWG of Castile and Leon (Fig. 5), as usual in the WD in CL1. The instability thus generated by this pattern resulted in 5 wildfires.

\subsubsection{CL2: case 20040618}

The trough at mid and low levels typical of CL2 deepens at both levels in this case (Fig. 6). The cold air mass at mid levels reaches $259.5 \mathrm{~K}$. However, the most significant factor is the $T_{850}$. The representative value of CL2 locates the $288 \mathrm{~K}$

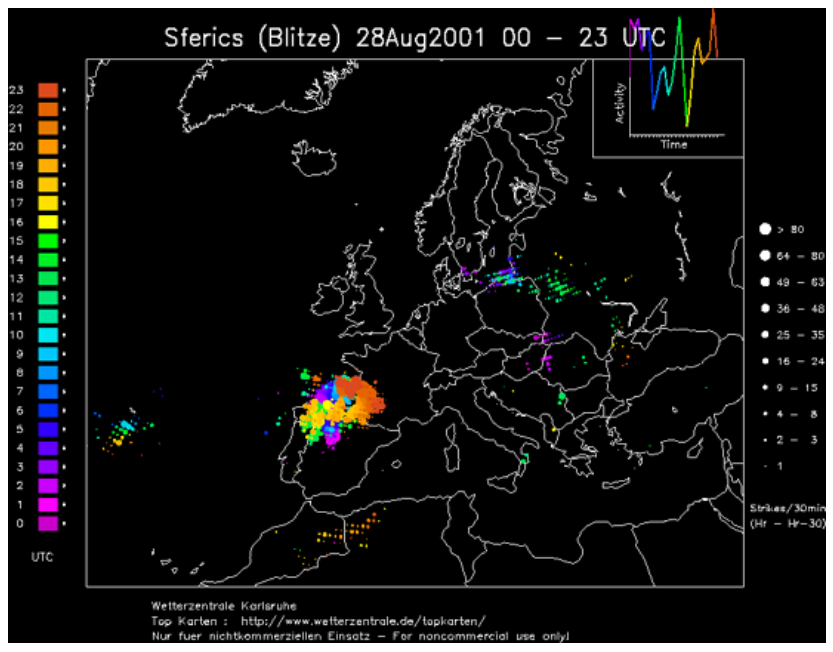

Fig. 5. Date: 28 August 2001, CL1. Spatial, temporal and intensity distribution of lightning events.
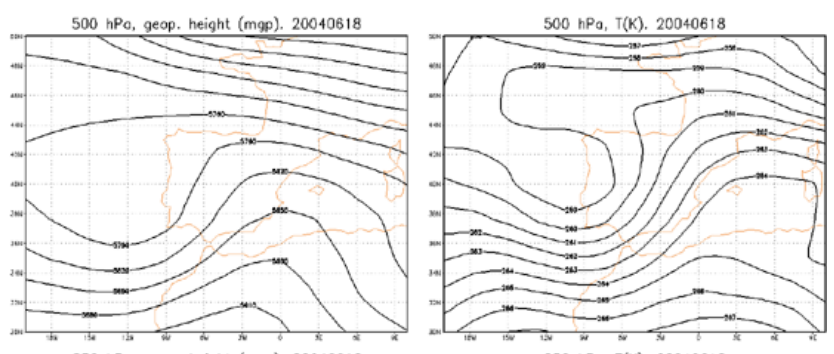

$850 \mathrm{hPo}$, geop. height (mgp). 2004081
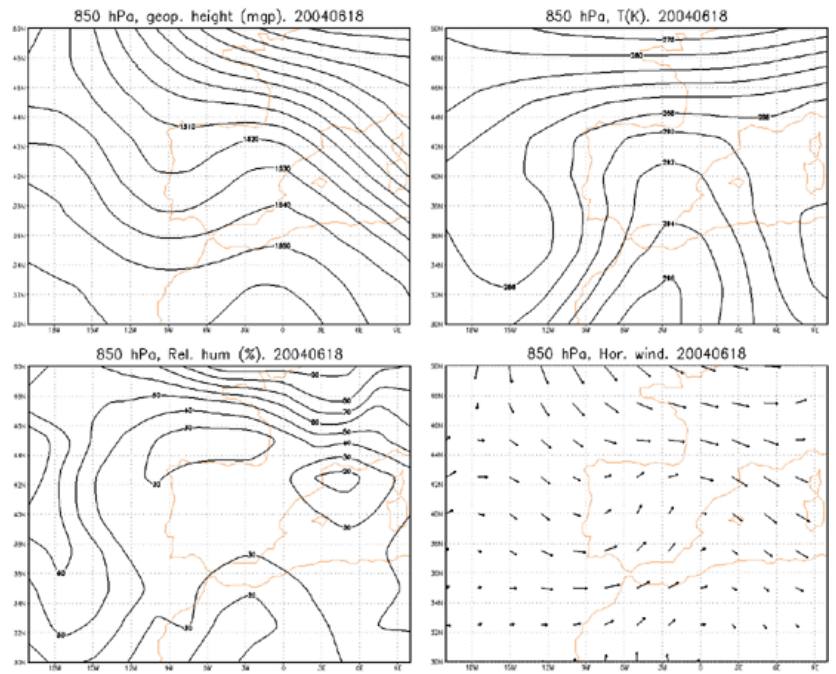

Fig. 6. NCEP reanalysis, 12:00 UTC. Date: 18 June 2004, CL2. The atmospheric fields shown are: $\phi_{500}(\mathrm{gpm}), T_{500}(\mathrm{~K}), \phi_{850}$ $(\mathrm{gpm}), T_{850}(\mathrm{~K}), \mathrm{rh}_{850}(\%)$ and wind direction at $850 \mathrm{hPa}$, from left to right.

isotherm to the north of the study area, but in this WD it is the $290 \mathrm{~K}$ isotherm that lies over that area. The deepening of the trough at $850 \mathrm{hPa}$ generates a wind pattern from the south which is more intense than the one typical of CL2. This wind pattern causes warm advection, more intense in the south of 


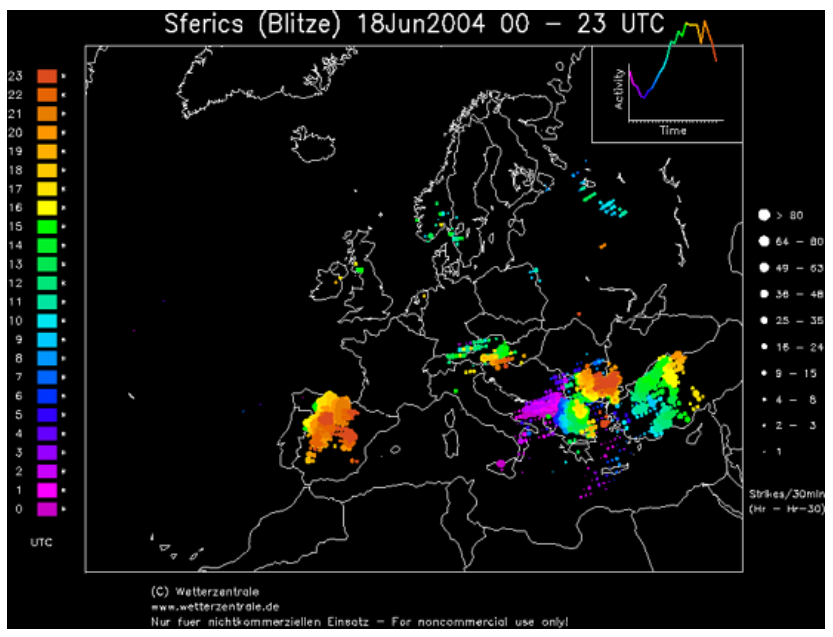

Fig. 7. Date: 18 June 2004, CL2. Spatial, temporal and intensity distribution of lightning events.

the study area, where more lightning was registered (Fig. 7). On that day there were 5 wildfires in the study area.

\subsubsection{CL3: case 20010728}

The trough from Central Europe typical of CL3 deepens and causes a low pressure system over the north of Spain with cold air (see Fig. 8). The low at $850 \mathrm{hPa}$ is not more intense than the one typical of CL3, but it lies over the Gulf of Cadiz, with a strong isopycnic gradient favouring winds from the $\mathrm{SE}$ in the study area. There were 16 wildfires on this day, mainly in the western part, although the spatial distribution of lightning covered the whole of Western Europe (Fig. 9).

\subsubsection{CL4: cases 20030812/20050618}

This cluster plays an important role because of the large number of wildfires registered in the WD, and we have therefore marked two different dates with slightly different characteristics. The spatial distribution of lightning (see Figs. 11 and 13) on both days covers mainly the west of the study area, but on 18 June 2005 there was also an important line of activity in the south. The $\phi_{500}$ shows a deepening of the African ridge when compared with values typical for CL4, and the $T_{500}$ is less cold (see Figs. 10 and 12) than the one typical for CL5. The divergent factor lies in $T_{850}$, with temperatures of more than $294 \mathrm{~K}$ keeping a very important vertical gradient with the $500 \mathrm{hPa}$ level. The high pressures at $850 \mathrm{hPa}$ inject very warm wind from the SE, more intensely so on 12 August 2003. In this case the activity affected mainly the NWG (15 wildfires detected, Fig. 11). On 18 June 2005 (12 wildfires detected, Fig. 13) the activity affected both the NWG and the SEG.

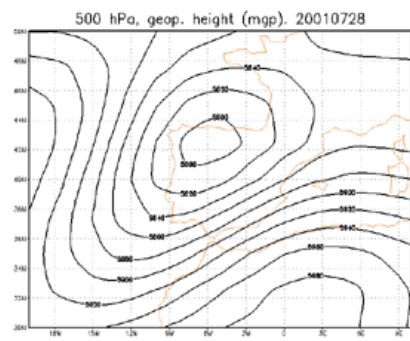

$850 \mathrm{hPo}$, geop. height (mgp). 20010728
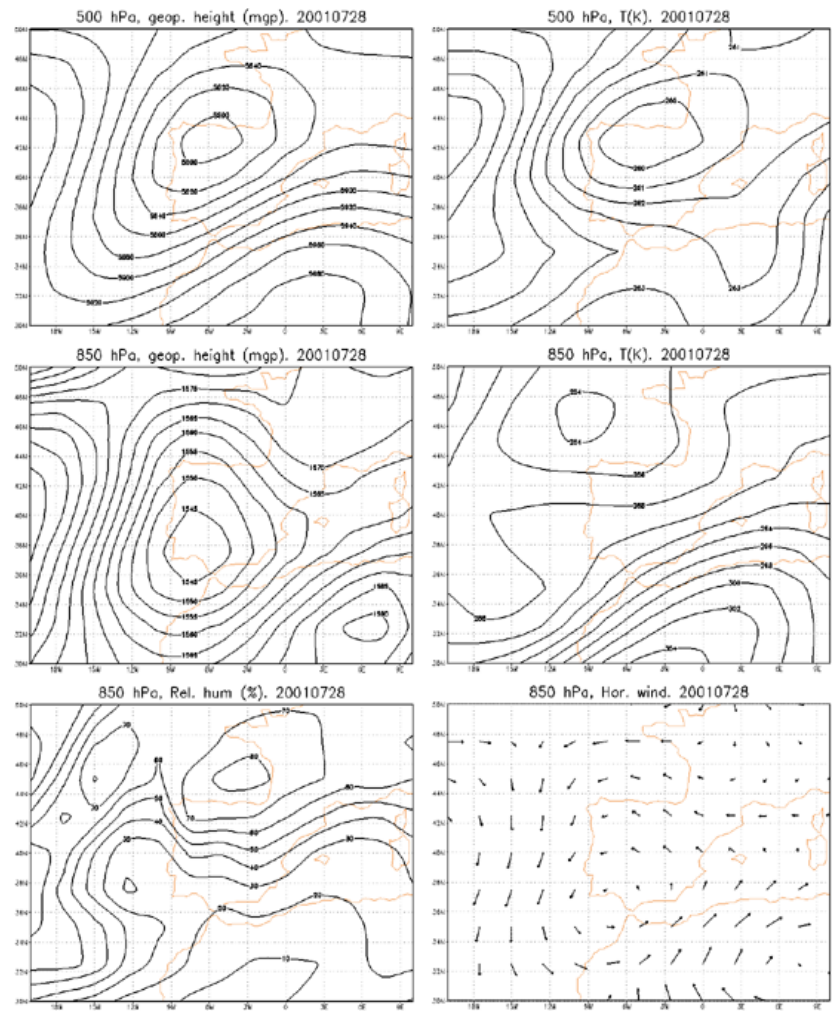

$850 \mathrm{hPo}$, Hor. wind. 20010728

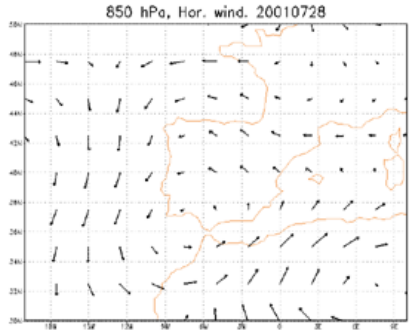

Fig. 8. NCEP reanalysis, 12:00 UTC. Date: 28 July 2001, CL3. The atmospheric fields shown are: $\phi_{500}(\mathrm{gpm}), T_{500}(\mathrm{~K}), \phi_{850}(\mathrm{gpm})$, $T_{850}(\mathrm{~K}), \mathrm{rh}_{850}(\%)$ and wind direction at $850 \mathrm{hPa}$, from left to right.

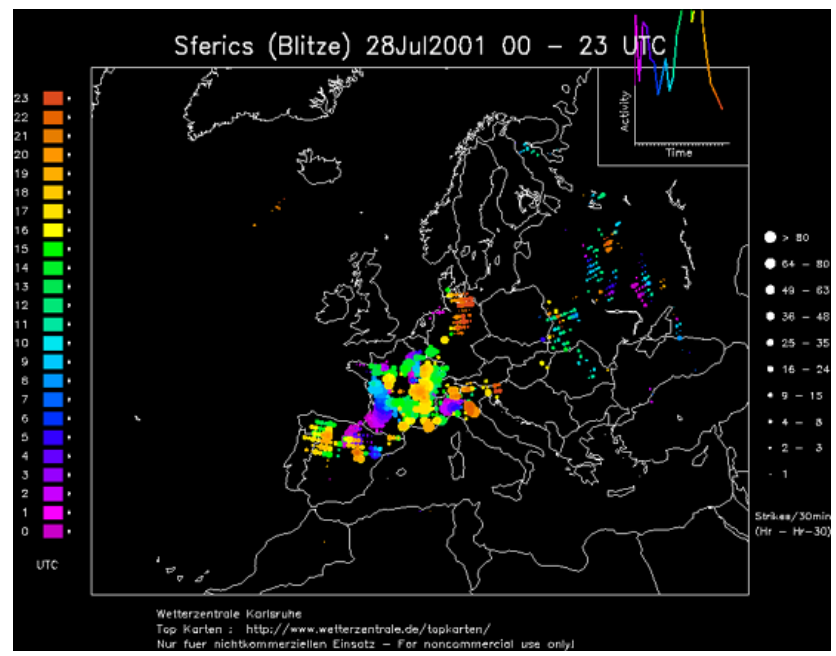

Fig. 9. Date: 28 July 2001, CL3. Spatial, temporal and intensity distribution of lightning events.

\subsubsection{CL5: cases 20010702/20050623}

In this cluster we have selected two cases, as in CL4. On 2 July 2001 (Fig. 14) the trough at mid levels is less well defined than in CL5. This is an anomalous situation in CL5, 

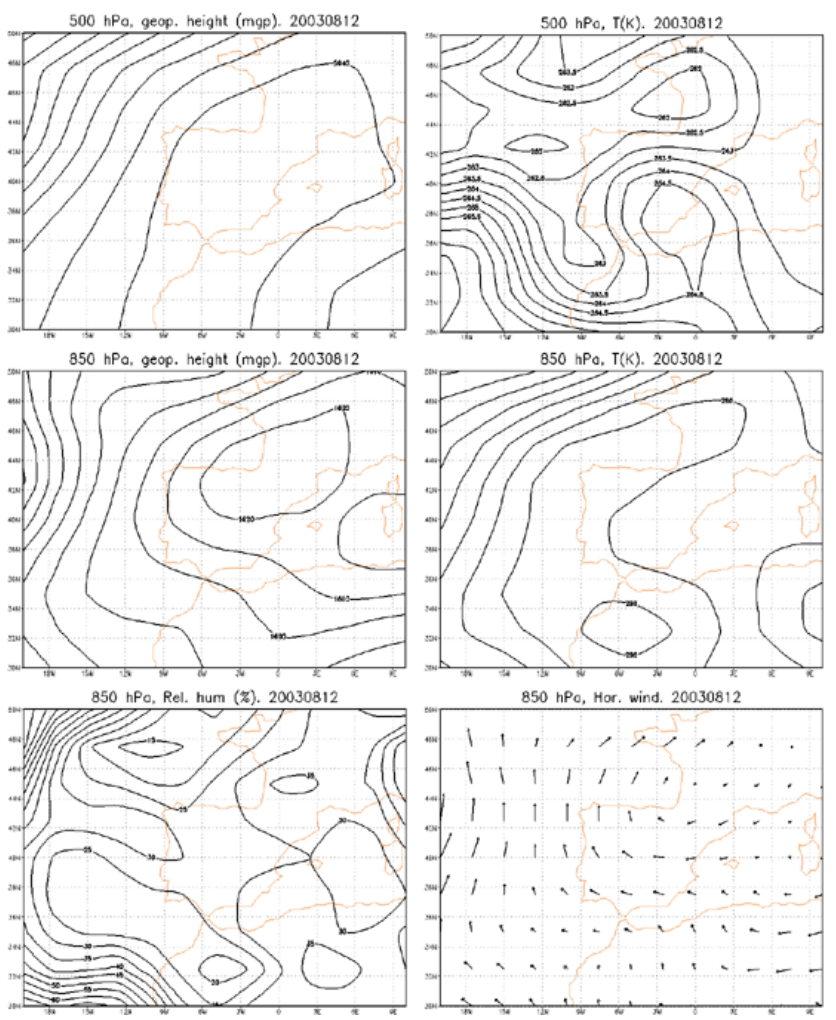

$850 \mathrm{hPo}$, Hor. wind. 20030812

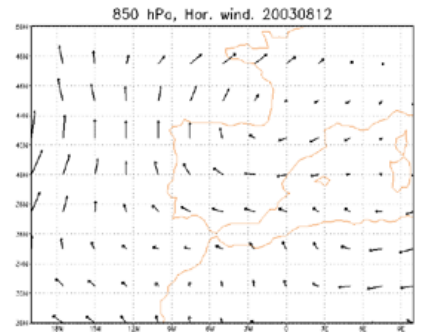

Fig. 10. NCEP reanalysis, 12:00 UTC. Date: 12 August 2003, CL4. The atmospheric fields shown are: $\phi_{500}(\mathrm{gpm}), T_{500}(\mathrm{~K}), \phi_{850}$ $(\mathrm{gpm}), T_{850}(\mathrm{~K}), \mathrm{rh}_{850}(\%)$ and wind direction at $850 \mathrm{hPa}$, from left to right.

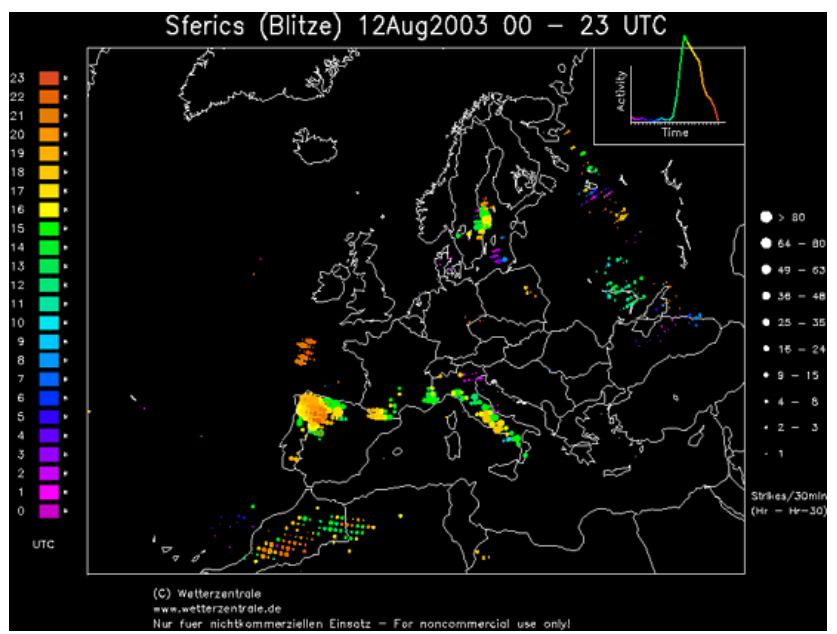

Fig. 11. Date: 12 August 2003, CL4. Spatial, temporal and intensity distribution of lightning events.

even though the $T_{500}$ shows a cold air mass in the NW of Spain, but with a warmer center to the SW. This is reflected in $\phi_{850}$ and causes $T_{850}>294 \mathrm{~K}$ in the NW of the study zone. The circulation at $850 \mathrm{hPa}$ is weak, but the relative humidity
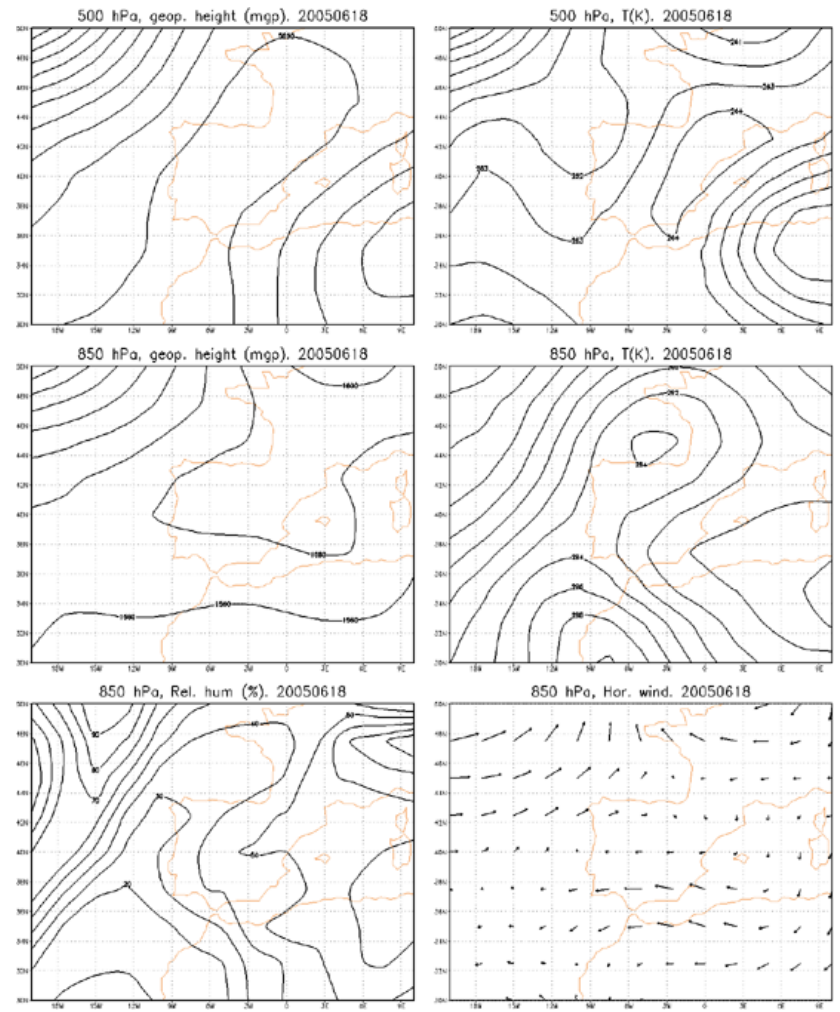

$850 \mathrm{hPo}$, Hor. wind. 20050618

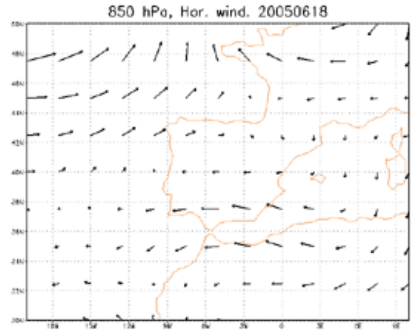

Fig. 12. NCEP reanalysis, 12:00 UTC. Date: 18 June 2005, CL4. The atmospheric fields shown are: $\phi_{500}(\mathrm{gpm}), T_{500}(\mathrm{~K}), \phi_{850}$ $(\mathrm{gpm}), T_{850}(\mathrm{~K}), \mathrm{rh}_{850}(\%)$ and wind direction at $850 \mathrm{hPa}$, from left to right.

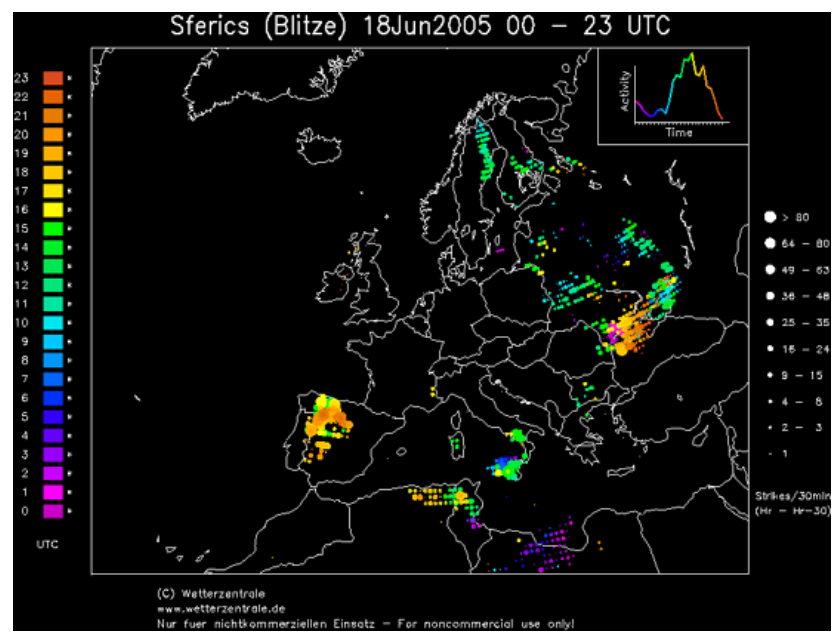

Fig. 13. Date: 18 June 2005, CL4. Spatial, temporal and intensity distribution of lightning events.

is very low. The high temperatures at low levels contribute more to the triggering of convection than the instability at mid levels. The cases of lightning (16 fires detected) were mostly observed in the $\mathrm{W}$ and moved during the day towards 

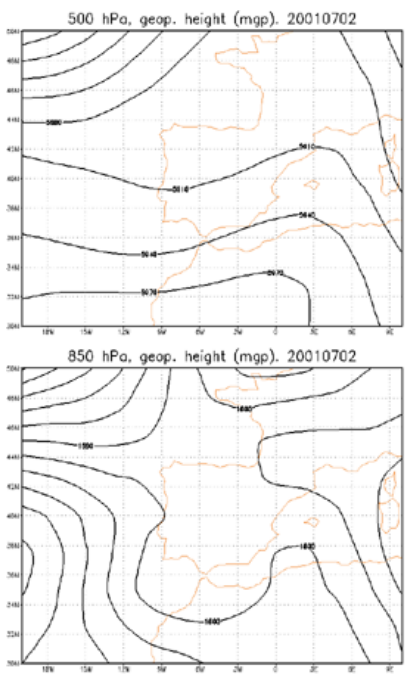

$850 \mathrm{hPo}$, Rel. hum (\%). 20010702
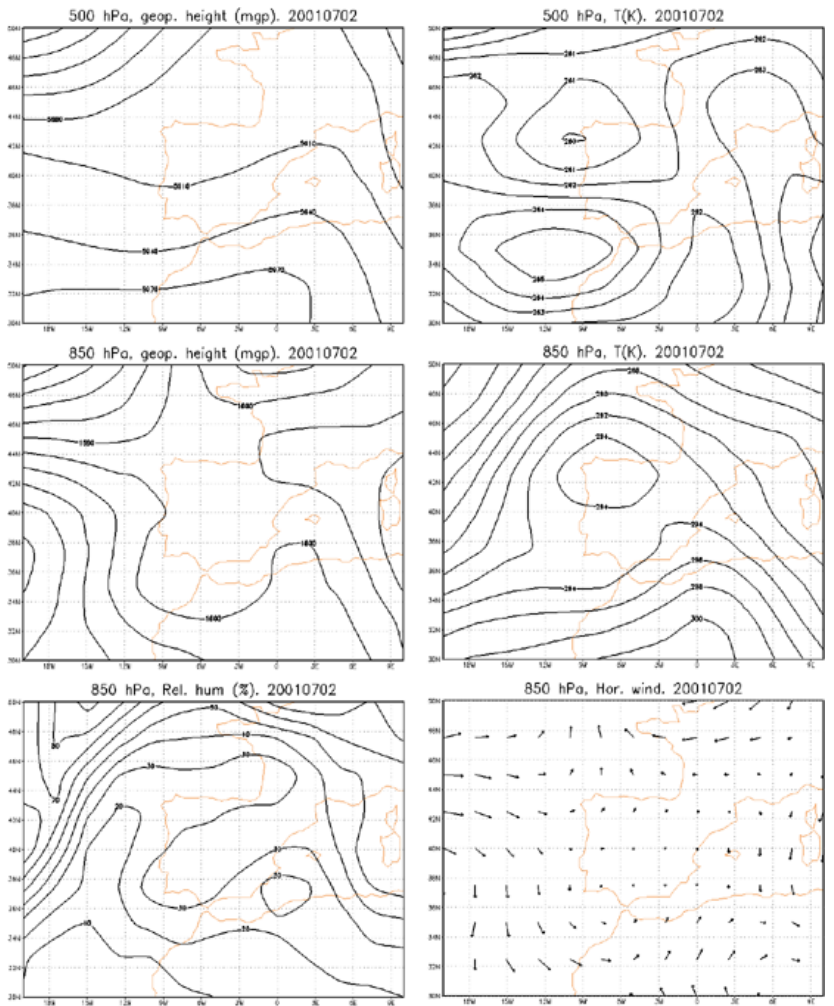

$850 \mathrm{hPo}, \mathrm{T}(\mathrm{K}) .20010702$

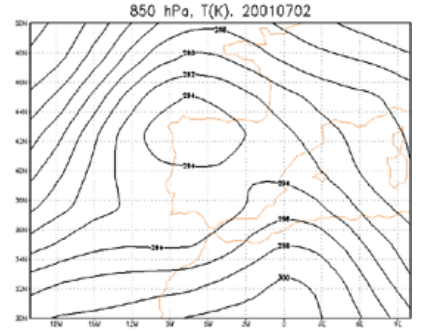

$850 \mathrm{hPo}$, Hor. wind. 20010702

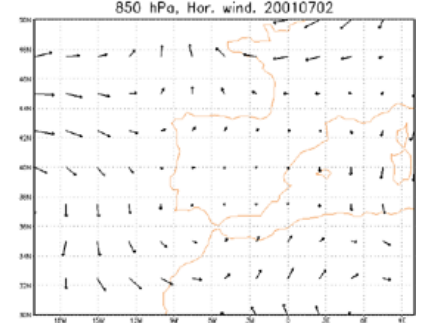

Fig. 14. NCEP reanalysis, 12:00 UTC. Date: 2 July 2001, CL5. The atmospheric fields shown are: $\phi_{500}(\mathrm{gpm}), T_{500}(\mathrm{~K}), \phi_{850}(\mathrm{gpm})$, $T_{850}(\mathrm{~K}), \mathrm{rh}_{850}(\%)$ and wind direction at $850 \mathrm{hPa}$, from left to right.

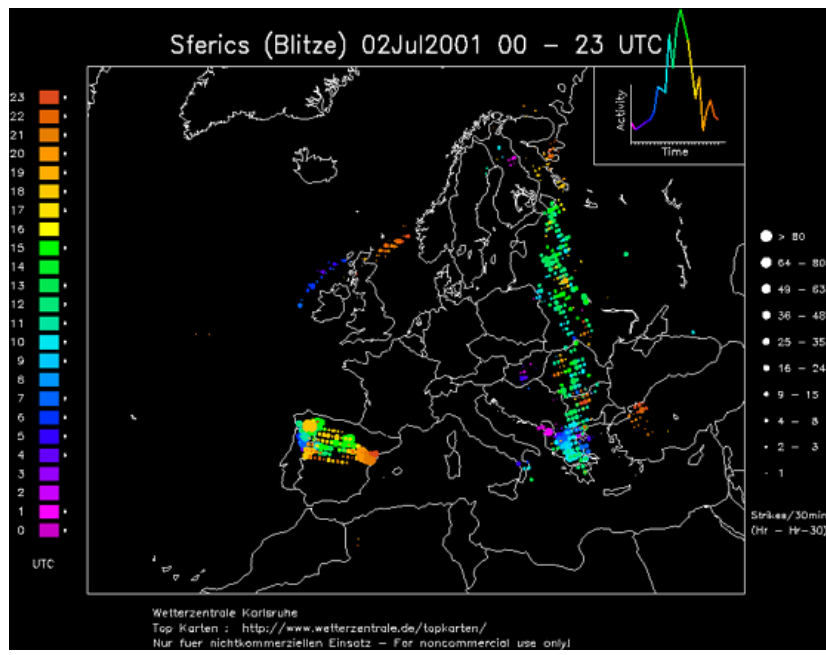

Fig. 15. Date: 2 July 2001, CL5. Spatial, temporal and intensity distribution of lightning events.

the E of Spain (Fig. 15). On 23 June 2005, $\phi_{500}$ shows the arrival from the NW of a trough less deep than the one typical of CL5 (Fig. 16), but it comes with a very cold air par-

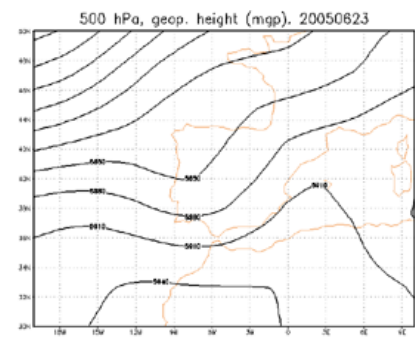

$850 \mathrm{hPo}$, geop. height (mgp). 20050623

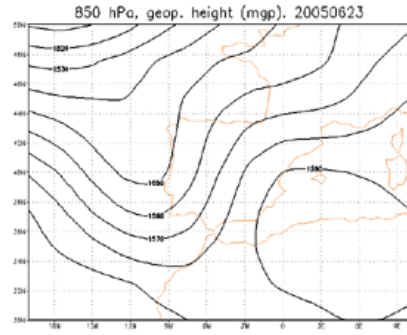

$850 \mathrm{hPo}$, Rel, hum (\%). 20050823
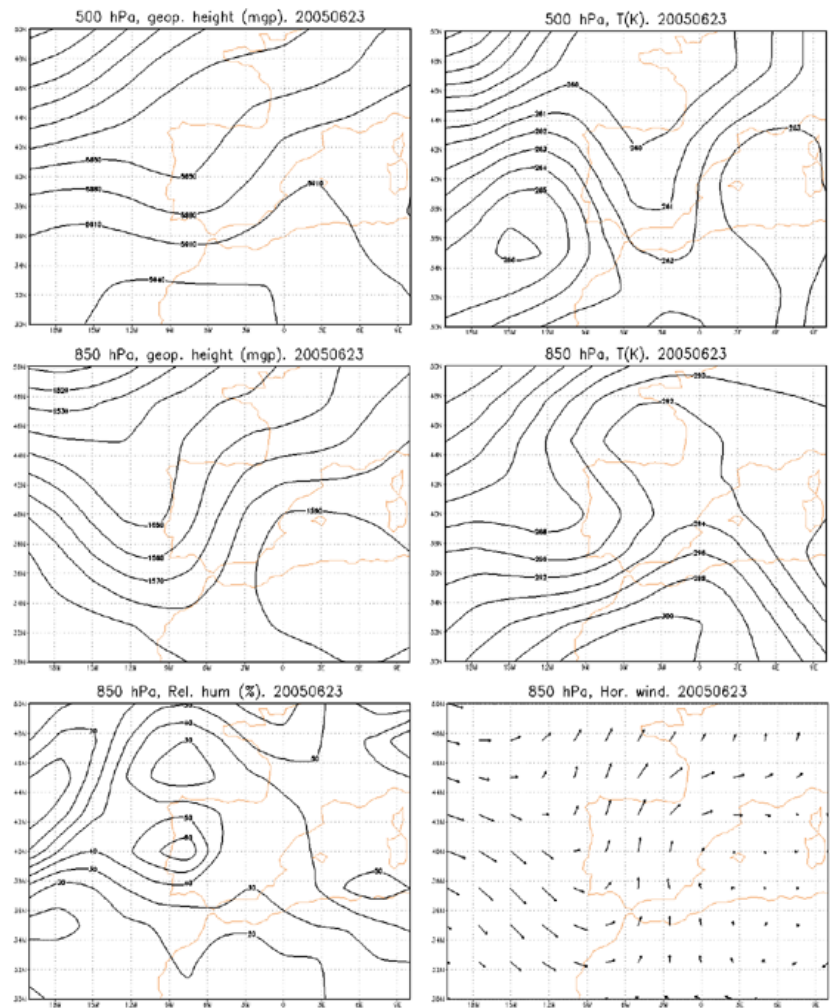

$850 \mathrm{hPo}, \mathrm{T}(\mathrm{K}) .20050623$

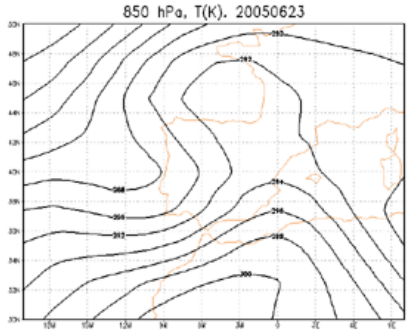

$850 \mathrm{hPc}$, Hor. wind. 20050623

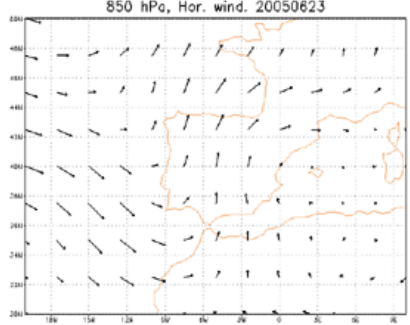

Fig. 16. NCEP reanalysis, 12:00 UTC. Date: 23 June 2005, CL5. The atmospheric fields shown are: $\phi_{500}(\mathrm{gpm}), T_{500}(\mathrm{~K}), \phi_{850}$ (gpm), $T_{850}(\mathrm{~K}), \mathrm{rh}_{850}(\%)$ and wind direction at $850 \mathrm{hPa}$, from left to right.

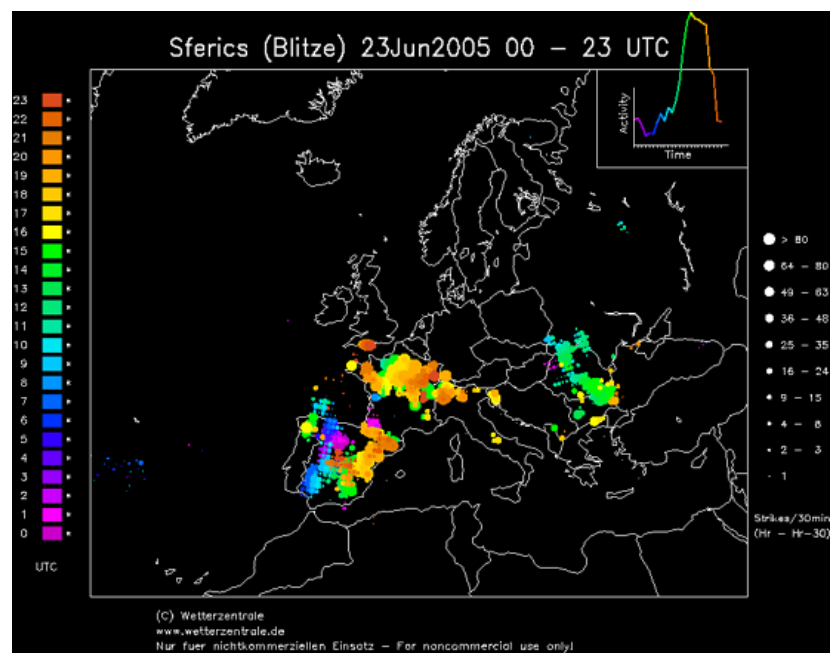

Fig. 17. Date: 23 June 2005, CL5. Spatial, temporal and intensity distribution of lightning events.

cel. The intense gradient associated with the $850 \mathrm{hPa}$ trough causes warm and dry advection from the south. The $500 \mathrm{hPa}$ disturbance moves fast crossing the Iberian Peninsula from $\mathrm{W}$ to E. The lightning map (11 fires detected) shows the 
evolution of this activity (see Fig. 17), which lies over the $\mathrm{W}$ of Spain early in the morning and in the afternoon over the E. When the progress becomes slower, the storm activity centers the whole day over the study area.

\section{Conclusions}

A classification has been set up for the atmospheric patterns corresponding to 376 wildfire days (WD) in the region of Castile and Leon, in the NW of Spain, during the period 1987-2006 in the months April-September. A wildfire day is defined as a day with at least one wildfire caused by lightning. The Center for the Defense against Fire (CDF) of the Regional Government in Castile and Leon runs an alarm system based on observers, satellite teledetection and lightning detection. The study area was divided in two according to topographic features and the distribution of wildfires: the NorthWestern Group (NWG) and the SouthEastern Group (SEG).

To classify the WD on a synoptic scale, the selected domain covered from $30^{\circ} \mathrm{N}$ to $50^{\circ} \mathrm{N}$ and from $20^{\circ} \mathrm{W}$ to $10^{\circ} \mathrm{E}$. In order to determine the atmospheric status during the WD at low and mid-levels, five meteorological fields were selected from the gridded reanalysis data from the NCEP: the geopotential height and the temperature at $500 \mathrm{hPa}$ and $850 \mathrm{hPa}$, respectively, the relative humidity and the horizontal wind at $850 \mathrm{hPa}$. The objective classification was carried out using Principal Component Analysis in T-mode, followed by Cluster Analysis. Days participating with similar loadings on the extracted components were clustered together. The Principal Component Analysis made it possible to select the main components of the data fields that account for $90 \%$ of the total variance: five components were stored for $\phi_{500}$, seven components were stored for $\phi_{850}$, nine for $T_{500}$, four for $T_{850}$, sixteen components for $\mathrm{rh}_{850}$, twelve and eleven for $u_{850}$ and $v_{850}$. The clustering process was applied to the matrix of 64 loadings and 376 events. The nonhierarchical k-means method was used, and finally five cluster elements were obtained.

The different atmospheric patterns corresponding to each cluster reveal well- defined individual characteristics. However, they all share one feature: the spatial configurations of the geopotential height and their temperature fields reveal the formation of synoptic environments that favour atmospheric instability, and consequently, convection: at $500 \mathrm{hPa}$ the patterns are characterised by the arrival of a cold trough or a low with a cold air mass from the NW of the Iberian Peninsula . At $850 \mathrm{hPa}$ there were flows from the SW, SE or S with advection of warm and dry air from the north of Africa. The synoptic configuration generated by this flow is due to the existence of a low or trough in the $\mathrm{W}$ or SW of the Iberian Peninsula, or to a high-pressure center in the NE of Spain.

Cluster 1 has $64 \mathrm{WD}$, cluster 2 has $80 \mathrm{WD}$ and cluster 3 has 76 WD. Cluster 4 has the lowest number of WD, only 53 , and cluster 5 has the maximum number of elements with
103 WD. All clusters present instability caused by the entrance of disturbances at mid levels coming with cold air parcels and advection of warm and dry air at low levels. This environment enhances the occurrence of convective phenomena.

CL1 features a low at mid and low levels. This cluster is particularly frequent in May. The pattern is more typical of spring than summer. CL2 is characterised by a summer trough at mid levels extending to low levels. The latter lies in advance and generates a counterclockwise rotation of winds in the south of Spain. Lightning occurs mainly in the SEG. In the months of June and September, most WD belong to CL3. A $500 \mathrm{hPa}$ trough tilted to the southwest over the Iberian Peninsula and the associated arrival of cold air from Europe are the main characteristics. The location of the $850 \mathrm{hPa}$ low favours the advection of warm and dry air from the north of Africa over Castile and Leon. The convective phenomena are favoured by the joint effect of both structures at low and mid levels. CL4 has the lowest number of WD, but registers a particularly large number of wildfires. At $850 \mathrm{hPa}$ a high pressure center defines an environment with high temperatures and a very low relative humidity. As a consequence of the configuration, there is advection of warm and dry air at $850 \mathrm{hPa}$ on the whole of the Iberian Peninsula, especially in the western half. At mid levels a ridge from the north of Africa lies over Spain. The arrival of a disturbance from the west increases the instability, particularly in the NWG. The formation of prefrontal storms is typical of this cluster. CL5 has $103 \mathrm{WD}$ and represents the most common synoptic situation in the months of July and August. The $\phi_{500}$ features a trough from the Atlantic with a longer wave length than in CL2. This disturbance affects first the western half of the Iberian Peninsula and then crosses it from $\mathrm{W}$ to $\mathrm{E}$. The trough at $850 \mathrm{hPa}$ is preceded by an African ridge. The boundary between both structures favours the advection of warm and dry air from northern Africa.

The wildfires in each cluster were evenly distributed in the NWG and the SEG, except in CL1 and CL4. The location of the disturbances at mid and low levels generates areas of greater instability over the NWG in both cases, explaining why around $60 \%$ of the wildfires occur in this group.

In each cluster we analysed the WD with more wildfires. The differences between the atmospheric patterns of these WD and the ones resulting from the CA are of particular interest for forecasting. In all cases we found an increase in disturbances, such as the trough or the low at $500 \mathrm{hPa}$ or the increase in $T_{850}$ and the decrease in $\mathrm{rh}_{850}$ due to a more intense African ridge.

Acknowledgements. The study was supported by the Regional Government of Castile and Leon through the grant LE031A08. The authors are grateful to Noelia Ramon for translating the paper into English and to María Alonso and Andrés Merino for their help with data processing.

We offer special thanks to the CDF for the wildfires data base. 
Edited by: R. Lasaponara

Reviewed by: L. Ghermandi and another anonymous referee

\section{References}

Anderberg, M. R.: Cluster analysis for applications, Academic Press, New York, 359 pp., 1973.

Bärring, L.: Spatial patterns of daily rainfall in central Kenya: application of principal component analysis, common factor analysis and spatial correlation, Int. J. Climatol., 7, 267-290, doi:10.1002/joc.3370070306, 1987.

Brooks, H. E., Doswell III, C. A., and Cooper, J.: On the environment of tornadic and nontornadic mesocyclones, Weather Forecast., 9, 606-618, 1994.

CE (European Commission): Forest fires in the south of the European Union, Preparatory study for the installation of a Common Information System on Forest Fires, European Commission, Directorate-General Agriculture, DG VI FII-2, 1996.

CE (European Commission): Common Information System on Forest Fires, 1985-1997 study, European Commission, DirectorateGeneral Agriculture, DG VI FII-2, 1998.

Flaningan, M. D. and Wotton, B. M.: Climate, weather and area burned, in: Forest Fires: Behavior and Ecological Effects, edited by: Johnson, E. A. and Miyanishi, K., Academic Press, San Diego, CA, 351-373, 2001.

Fuquay, D. M., Baughman, R. G., and Latham, D. J.: A model for predicting lightning fire ignition in wildland fuels, USDA Forest Service Research Paper INT-217 (available from USDA Forest Service - RMRS, 324 25th St., Ogden, UT 84401), Intermountain Forest and Range Experiment Station, Ogden, UT, 22 pp., 1979.

Gong, X. and Richman, M. B.: On the application of cluster analysis to growing season precipitation data in North America east of the Rockies, J. Climate, 8, 897-931, 1995.

Jolliffe, I. T.: Principal Component Analysis, Springer, New York, 487 pp., 2002.

Kassomenos, P.: Synoptic circulation control on wild fire occurrence, Phys. Chem. Earth, 35, 544-552, doi:10.1016/j.pce.2009.11.008, 2010.

Kunkel, K. K.: Surface energy budget and fuel moisture, in: Forest Fires-Behaviour and Ecological Effects, edited by: Johnson, E. A. and Miyanishi, K., Academic Press, San Diego, CA, 303-350, 2001.

Millán, M. M., Estrela, M. J., and Badenas, C.: Meteorological Processes Relevant to Forest Fire Dynamics on the Spanish Mediterranean Coast, J. Appl. Meteorol., 37, 83-100, 1998.
Morris, W. G.: Lightning storms and fires. Pacific Northwest Forest Experiment Station, Portland, OR, 27 pp., 1934.

Pereira, M. G., Trigo, R. M., da Camara, C. C., Pereira, J. M. C., and Leite, S. M.: Synoptic patterns associated with large summer forest fires in Portugal, Agr. Forest Meteorol., 129, 11-25, doi:10.1016/j.agrformet.2004.12.007, 2005.

Petersen, W. A. and Rutledge, S. A.: On the relatiuonships between cloud-to-ground lightning and convective rainfall, J. Geophys. Res., 103, 14025-14040, doi:10.1029/97JD02064, 1998.

Preisendorfer, R. W.: Principal component analysis in meteorology and oceanography, Elsevier, New York, 425 pp., 1988.

Pyne, S. J., Andrews, P. L., and Laven, R. D. Introduction to Wildland Fire, 2nd edn., John Wiley \& Sons, New York, 808 pp., 1996.

Richman, M. B.: Rotation of principal components, J. Climatol., 6(3), 293-335, doi:10.1002/joc.3370060305, 1986.

Rivas, L. and de Pablo, F.: Analysis of convective precipitation in the western Mediterranean Sea though the use of cloud-to-ground lightning. Atmos. Res., 66(3), 189-202, doi:10.1016/S0169-8095(02)00160-6, 2003.

Roads, J. M., Ueymshi, K., Chen, S.-C., Alpert, J., and Fujioka, F.: Medium-range fire weather forecast, Int. J. Wildland Fire, 1, 159-176, 1991.

Rorig, M. L. and Ferguson, S. A.: Characteristics of Lightning and Wildland Fire Ignition in the Pacific Northwest, J. Appl. Meteorol., 38, 1565-1575, 1999.

Skinner, W. R., Flannigan, M. D., Stoks, B. J., Martell, D. L., Wotton, B. M., Todd, J. B., Mason, J. A., Logan, K. A., and Bosch, E. M.: A $500 \mathrm{hPa}$ synoptic wildland fire climatology for large Canadian forest fires, Theor. Appl. Climatol., 71, 157-169, 2002.

Swetnam, T. W. and Betancourt, J. L.: Fire-SO relations in SW United States, Science, 249, 1017-1019, 1990.

Trigo, R. M., Pereira, J. M. C., Pereira, M. G., Mota, B., Calado, T. J., DaCamara, C. C., Santo, F. E.: Atmospheric conditions associated with the exceptional fire season of 2003 in Portugal, Int. J. Climatol., 26(13), 1741-1757, doi:10.1002/joc.1333, 2006.

Viegas, D. X., Bovio, G., Ferreira, A., Nosenzo, A., and Sol, B.: Comparative study of various methods of fire danger evaluation in southern Europe, Int. J. Wildland Fire, 9(4), 235-246, doi:10.1071/WF00015, 1999.

Wierzchowski, J., Heathcott, M., and Flannigan, M. D.: Lightning and lightning fire, central cordillera, Canada, Int. J. Wild. Fire, 11(1), 41-51, 2002.

Yarnal, B.: Synoptic climatology in environmental analysis, London and Florida, Belhaven Press, 195 pp., 1993. 